\title{
Multidrug resistance protein structure of Trypanosoma evansi isolated from buffaloes in Ngawi District, Indonesia: A bioinformatics analysis
}

\author{
Moh. Mirza Nuryady ${ }^{1,2}$ (D), Raden Wisnu Nurcahyo ${ }^{2,3}$ (D), Iin Hindun ${ }^{1}$ (D) and Diani Fatmawati1 ${ }^{(\mathbb{D}}$
}

1. Department of Biology Education, Faculty of Teacher Training and Education, Universitas Muhammadiyah Malang, Malang, Indonesia; 2. Master Program of Veterinary Science, Faculty of Veterinary Medicine, Universitas Gadjah Mada, Yogyakarta, Indonesia; 3. Department of Parasitology, Faculty of Veterinary Medicine, Universitas Gadjah Mada, Yogyakarta, Indonesia.

Corresponding author: Raden Wisnu Nurcahyo,e-mail: wisnu-nc@ugm.ac.id

Co-authors: MMN: mirzanuryady@umm.ac.id, IH: iinhindun@umm.ac.id, DF: dianifatmawati87@umm.ac.id Received: 14-07-2020, Accepted: 03-11-2020, Published online: 06-01-2021

doi: www.doi.org/10.14202/vetworld.2021.33-39 How to cite this article: Nuryady MM, Nurcahyo RW, Hindun I, Fatmawati D (2021) Multidrug resistance protein structure of Trypanosoma evansi isolated from buffaloes in Ngawi District, Indonesia: A bioinformatics analysis, Veterinary World, 14(1): 33-39.

\begin{abstract}
Background and Aim: Trypanosomiasis, also known as surra, is an infectious disease with a wide host spectrum. In Indonesia, this disease is caused by Trypanosoma evansi. Various trypanocidal drugs have been used to treat this pathogen and subsequent disease. Yet, the long-term trypanocidal administration generates drug-resistant T. evansi. Some have identified genetic alterations in $T$. evansi transporter protein-coding genes that may be responsible for drug resistance. The Multidrug Resistance Protein E (MRPE) gene is a likely candidate gene responsible for the individual resistance. To date, no research has focused on T. evansi MRPE (TevMRPE) in this context. Hence, this research aimed at analyzing and characterizing the TevMRPE gene and protein using a bioinformatics approach.
\end{abstract}

Materials and Methods: T. evansi was isolated from buffalo suffering from surra in Ngawi Regency, Indonesia. Isolated T. evansi was inoculated and cultured in male mice. The T. evansi genome was isolated from mouse blood with a parasitemia degree as high as $10^{5}$. A polymerase chain reaction procedure was conducted to amplify the putative MRPE coding gene. The amplicon was sequenced and analyzed using MEGA X, BLAST, and I-tasser softwares.

Results: The putative TevMRPE coding gene showed sequence similarity as high as 99.79\% against the MRPE gene from Trypanosoma brucei gambiense. The protein profile and characteristics depicted that the putative TevMRPE protein was related to a family of Adenosine Triphosphate-Binding Cassette (ABC) transporter proteins. This family of transporter proteins plays a crucial role in the resistance toward several medicines.

Conclusion: The obtained gene sequence in this research was identified as the TevMRPE. This gene is homologous to the T. brucei gambiense MRPE gene and possesses ligand active sites for Adenylyl Imidodiphosphate. In addition, MRPE contains enzyme active sites similar to the cystic fibrosis transmembrane conductance regulator. These data suggest that ABC transport proteins, like MRPE, may be necessary to confer trypanocidal drug resistance in T. evansi.

Keywords: bioinformatics, buffaloes, multidrug resistance protein E, protein structure, Surra, Trypanosoma evansi.

\section{Introduction}

Trypanosoma evansi is a blood parasite that causes surra in a variety of hosts [1]. The reported parasite is not only deadly to cattle but also infects humans in some Asia countries [2]. The government typically uses trypanocidal drugs to combat surra. The trypanocides used today are similar to those first used in the 1920s: Suramin, isometamidium, diminazene, and quinapyramine dan melarsomine [3]. However, the long-term use of these drugs lead to a drug-resistant $T$. evansi infection [4,5]. Many studies in Indonesia have characterized resistant surra cases. Subekti et al. [6] reported that T. evansi isolated from

Copyright: Nuryady, et al. Open Access. This article is distributed under the terms of the Creative Commons Attribution 4.0 International License (http://creativecommons.org/licenses/ by/4.0/), which permits unrestricted use, distribution, and reproduction in any medium, provided you give appropriate credit to the original author(s) and the source, provide a link to the Creative Commons license, and indicate if changes were made. The Creative Commons Public Domain Dedication waiver (http:// creativecommons.org/publicdomain/zero/1.0/) applies to the data made available in this article, unless otherwise stated. different areas were resistant toward isometamidium. Later it was shown that Trypanosoma resistance was due to the decrease of transporter protein uptake function [7]. Consistent with that observation, a mutation in the Trypanosoma brucei Adenosine Transporter coding gene (TbAT1) led to the Trypanosoma resistance toward diminazene aceturate [8]. Moreover, Delespaux et al. [9] reported the presence of a GAA codon insertion within the Trypanosoma congolens Adenosine Triphosphate (ATP)-Binding Cassette (ABC) Transporter coding gene to confer resistance to isometamidium. There are several other transporter protein families assumed to be responsible in Trypanosoma medicine resistance. One protein that is rarely considered is the multidrug resistance protein (MRP).

MRP is part of the ABC transporter family and is necessary for some resistance in Trypanosoma species toward trypanocides; particularly ivermectin, melarsoprol, and benznidazole [10,11]. The common MRP gene analyzed from $T$. brucei species is TbMRPA [12]. To date, there is only one study focused on the MRP 
gene in T. evansi [13]. However, Nuryady et al. [13] only characterized and analyzed the phylogenetic profile of $T$. evansi MRP to other species. In addition, the primer sequences amplified regions of the MRPE gene that limits analyzing the family relationship among sub-species.

This study aimed to analyze the $T$. evansi MRPE (TevMRPE) protein using TevMRPE gene by bioinformatics. This bioinformatics analysis of the TevMRPE coding gene is crucial to gain more detailed information about the characters and roles of this protein. This information will provide a deeper understanding of Trypanosoma medicine resistance.

\section{Materials and Methods}

\section{Ethical clearance}

All the experimental protocols employed in this research were examined and approved by the Veterinary Faculty Ethical Clearance Committee at Gadjah Mada University in Indonesia. Based on the approval letter No. 0024/EC-FKH/Int./2018, all procedures were conducted with strict adherence to the principles of laboratory animal care.

\section{Study period and location}

This research was conducted from January 2018 to December 2020. The implementation of the research was carried out at the Parasitology Laboratory, Faculty of Veterinary Medicine, Universitas Gadjah Mada, Indonesia, Bioscience Laboratory of NODAI, Japan, and Biology Laboratory of Universitas Muhammadiyah Malang, Indonesia.

\section{Isolation and identification}

The parasite was obtained from the pooled blood of 88 buffalo, which were positively identified with Surra in Ngawi Regency, Indonesia. The identification of $T$. evansi was conducted based on in vivo test and morphological structure. The in vivo test was applied by inoculating and culturing the parasite in 3-monthold male mice (Mus musculus strain Balb-C from Central University Laboratory UGM) by intraperitoneal injection. After $24 \mathrm{~h}$, the mice were observed the parasitemia levels by drawing blood from the vena coccygea and observing the number also the morphology of T. evansi under a microscope (Olympus, CX22 series). Mice blood identified with more than 20 T. evansi in the microscope field view were recognized as a high level of parasitemia. In this condition, the mice were euthanatized, blood was taken, and stored at $4{ }^{\circ} \mathrm{C}$ until DNA extraction.

\section{DNA extraction}

DNA was extracted from mouse blood containing T. evansi using the DNA DNeasy Blood and Tissue kit (Qiagen, Hilden, Germany). The mouse blood was mixed with phosphate-buffered saline to a volume of $200 \mu \mathrm{L}$. Proteinase K $(20 \mu \mathrm{L})$ was added into the mixture and incubated at $60^{\circ} \mathrm{C}$ for $5 \mathrm{~min}$ using a shaker incubator. An equal volume of absolute alcohol was added to the mixture and the final mixture was loaded onto a GD column where the DNA was bound for subsequent washes (see company protocol for details). DNA was eluted from the GD column using $100 \mu \mathrm{L}$ elution buffers.

\section{DNA amplification}

A primer pair was developed from the MRPE T. brucei gene sequence: The reverse primer was 5'ATGAACGCTGACTCTGGTGA3' and the forward primer was 5'GTAAGCAAG GCATTGTGGAA3'. A master mix was prepared with $25 \mu \mathrm{L} 2 \times$ Go Taq Green polymerase Master Mix (Thermo Fisher Scientific, cot: K1081), $10 \mu \mathrm{L}$ template DNA, primer (F:1 $\mu \mathrm{L}$, $\mathrm{R}: 1 \mu \mathrm{L}$ ), and distilled water to a total volume of $50 \mu \mathrm{L}$. Polymerase Chain Reaction (PCR) reactions were carried out on a Thermocycler (Labcycler Gradient, SensoQuest). The PCR reaction parameters were: Predenaturation at $94^{\circ} \mathrm{C}$ for $7 \mathrm{~min}$, denaturation at $94^{\circ} \mathrm{C}$ for $30 \mathrm{~s}$, annealing at $58^{\circ} \mathrm{C}$ for $30 \mathrm{~s}$, extension at $72^{\circ} \mathrm{C}$ for $60 \mathrm{~s}$, and termination at $72^{\circ} \mathrm{C}$ for $5 \mathrm{~min}$ for a total of 35 cycles.

\section{Sequencing and bioinformatics analysis}

Sanger sequencing was conducted at First Base in Malaysia. DNA sequences were analyzed using MEGA 10 version and BLAST to obtain the protein composition and sub-species relationship. The protein composition was analyzed using I-tasser (https://zhanglab.ccmb.med.umich.edu/I-TASSER/) to predict the gene ontology, protein 3D structure, ligand binding sites, and active sites of the protein. The protein structure modeling obtained was used to compared homology to the other several related proteins. Structure differences were modeled using PyMol (Schrödinger, Inc., NY, USA).

\section{Results}

\section{DNA sequence and phylogeny analysis}

Sanger sequencing was employed to characterize the putative TevMRPE gene in relation to other sub-species. The gene was 939 nucleotides long. Blastx (MEGA X-highly similar sequence) was used to analyze the homologous relationship between sub-species. The alignment results showed that $T e v \mathrm{MRPE}$ sequence was identical to five sub-species $(100 \%$ query coverage). The sequences were Trypanosoma brucei gambiense DAL972 MRPE (XM_011774747.1), T. brucei gambiense DAL972 chromosome 4 complete (FN554967.1), Trypanosoma brucei brucei mRNA MRPE (AJ318886.1), T. brucei brucei TREU927 MRPE (XM_839505.1), and T. brucei GUTat10.1 chromosome 4 complete (AC087327.7). In addition, the homologous identity compared to the MRPE T. evansi putative sequence and to MRPE T. brucei gambiense (XM_011774747.1) was 99.79\%. The analysis results are summarized in Figure-1.

\section{Protein alignment of the putative TevMRPE gene}

The putative TevMRPE gene sequence was analyzed using the Blastx to get the amino acid sequence as well as the protein alignment against 
other sub-species. The analysis showed that there were five protein sequences with query coverage of at least $83 \%$. These five proteins were classified into two groups. The first group consisted of Trypanosoma brucei equiperdum MRPA (RHW73256.1) with 100\% homology. The other four MRPs (T. brucei gambiense MRPE [XP_011773049.1], T. brucei brucei MRPE [CAC83023.1], Trypanosoma equiperdum MRPA [SCU69648.1], and T. brucei brucei MRPE [XP_844598.1]) showed 99.6\% homology. The results are shown in Table-1.

\section{Conserved protein domain analysis}

As shown in Figure-2, the protein sequence translated from the putative TevMRPE gene aligns with many proteins from the $\mathrm{ABC}$ transporter superfamily (PTZ00243): $A \mathrm{BC}$ domain 1 multidrug resistance-associated protein subfamily $\mathrm{C}$ (cd03250), multidrug resistance-associated protein MRP (TIGR00957), ABCtype bacteriocin/antibiotic exporters (COG2274), and ABC Transporter (pfam00005).

\section{Predicting the putative TevMRPE protein using bioin-} formatics analysis

To predict the TevMRPE protein template, protein threading was performed by aligning the TevMRPE protein target sequence with similar template protein sequences obtained from the Protein Data Bank (PDB, i.e., structure of the human MRP 1 Nucleotide Binding Domain 1 [NBD1]); 6BZS (Human ABCC6 NBD1 in Apo state); 6BZS (Human ABCC6 NBD1 in Apo state); 3WME (Crystal structure of an inward-facing eukaryotic $\mathrm{ABC}$ multidrug transporter); 1R0Z (Phosphorylated Cystic fibrosis transmembrane conductance regulator (CFTR) NBD1 with ATP; 5U71 (Structure of human CFTR); 6BZS [Human ABCC6 NBD1 in Apo state]; and 1Q3H [mouse CFTR NBD1 with AMP.PNP]). PDB templates that align well with the target protein are assumed to possess the similar protein structures [14]. The protein threading results showed that there were three template sequences that resembled the TevMRPE protein structure (Table-2). These three templates were $2 \mathrm{cbz}$ (Structure of the human MRP 1 NBD1); 6bzs (Human ABCC6 NBD1 in Apo state); and 6bzs (Human ABCC6 NBD1 in Apo state).

\section{Prediction model of the TevMRPE protein structure}

Five protein models were generated based on the modeling prediction results. However, the first model was the closest representation of MRPE, possessing

Table-1: Results from the protein alignment analysis of the T. evansi MRPE protein.

\begin{tabular}{llcc}
\hline No. & Name of protein sequence & Accession No. & Query coverage \\
\hline 1. & MRPA of Trypanosoma brucei equiperdum & RHW73256.1 & $100 \%$ \\
2. & MRPE of Trypanosoma brucei gambiense & XP_011773049.1 & $99.6 \%$ \\
3. & MRPE of Trypanosoma brucei brucei & CAC83023.1 & $99.6 \%$ \\
4. & MRPA of Trypanosoma equiperdum & XP_844598.1 & $99.6 \%$ \\
5. & MRPE of Trypanosoma brucei brucei & $99.6 \%$ \\
\hline
\end{tabular}

T. evansi MRPE $=$ Trypanosoma evansi Multidrug Resistance Protein E

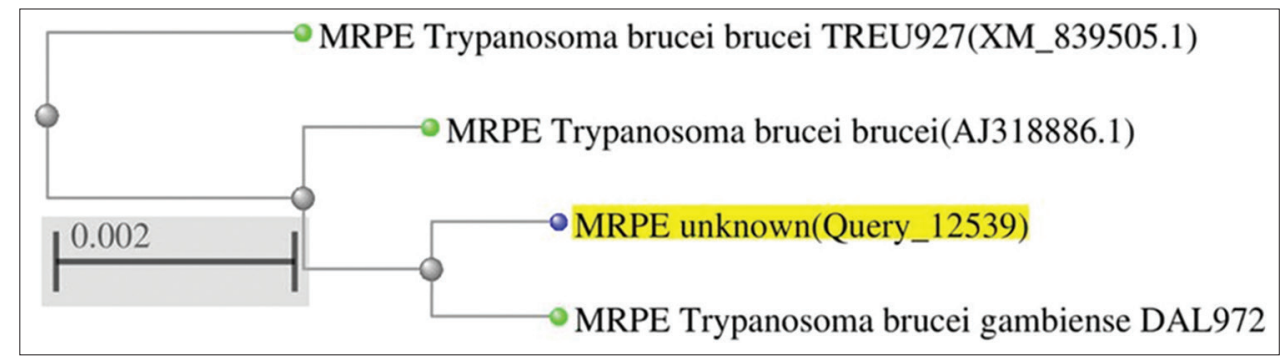

Figure-1: Phylogenetic diagram of multidrug resistance protein E Trypanosoma evansi analyzed using megablast.

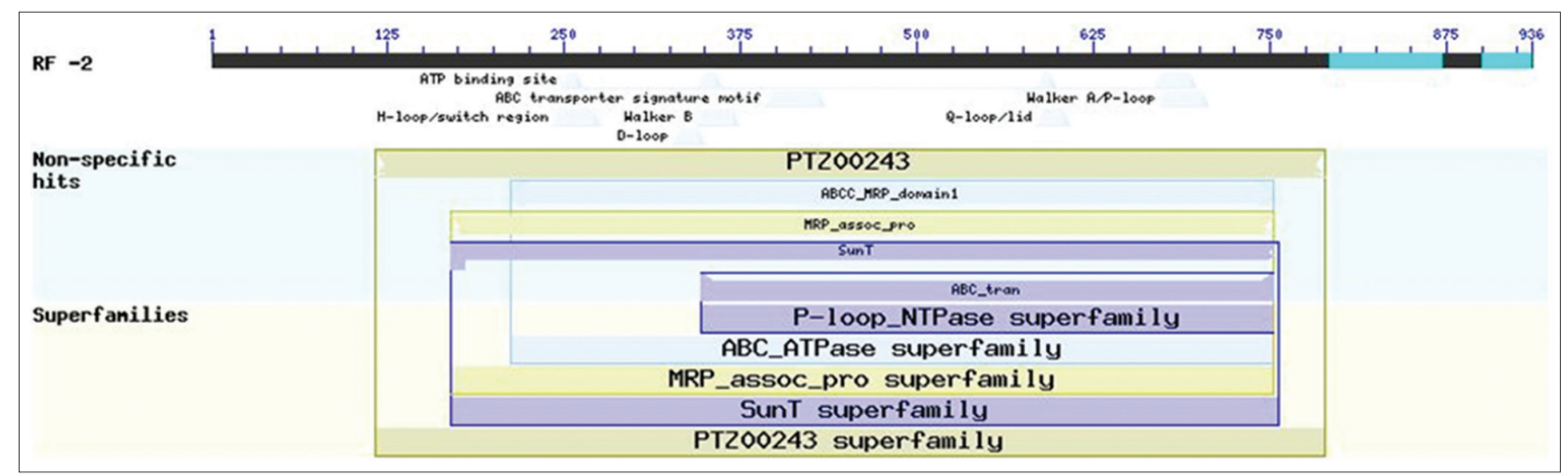

Figure-2: The results analysis of conserved protein using online Blast. 
Table-2: The protein threading results of the T. evansi MRPE protein.

\begin{tabular}{lcccc}
\hline No. PDB hit & Coverage & Norm. Z-score & Protein name & Function \\
\hline 1. & 2cbzA & 0.84 & 3.36 & Human MRP 1 nucleotide-binding domain 1 \\
2. & 6bzsA & 0.83 & 3.85 & Human ABCC6 nucleotide-binding domain 1 in Apo state Transport protein \\
3. & 6bzsA & 0.83 & 4.06 & Human ABCC6 nucleotide-binding domain 1 in Apo state Transport protein \\
\hline
\end{tabular}

- Coverage represents the coverage of the threading alignment and is equal to the number of aligned residues divided by the length of query protein. Norm. Z-score is the normalized Z-score of the threading alignments. Alignment with a Normalized Z-score >1 mean a good alignment and vice versa. T. evansi MRPE=Trypanosoma evansi Multidrug Resistance Protein E

the highest C-score $(-0.66)$, estimated TM-score $(0.63 \pm 0.14)$, and root-mean-square deviation (RMSD) (7.3 $\pm 4.2 \AA)$ (Figure-3).

Five predicted protein ligand sites were identified. The ligand site with the highest C-score $(0.8)$ was Adenylyl Imidodiphosphate (ANP-PMP). The modeling prediction results of the five ligand sites are shown in Table-3. The ligand site prediction of the TevMRPE protein is found in Figure-4.

\section{Enzyme commission (EC) prediction and its active site}

An EC number is a numeric classification based on the chemical reaction catalyzed. The closest model enzyme (Model 1; C-score, 0.414; and TM-score, 0.804 ) relating to the TevMRPE protein was classified as a transport protein (EC number 3.6.3.49), which has five active sites for enzyme binding (Figure-5).

\section{Gene ontology prediction}

Gene ontology predicts and/or identifies the molecular function, biological process, and cellular location of the TevMRPE protein (Table-4). The two highest molecular function predictions are ATP Binding and ATPase-coupled transmembrane transporter activity with GO-scores of 0.95 and 0.48 , respectively. This protein is involved in biological processes such as transmembrane transport and obsolete ATP catabolic process with GO-scores of 0.48 , each. This protein is suggested to be located in the plasma membrane and membrane integral component with GO-scores of 0.48 for both.

\section{Discussion}

The primers were designed from T. brucei because there are no reports about MRPE gene of T. evansi in the GenBank and due to the research result [1] that $T$. brucei has a closer relationship with T. evansi than other species. The result of the primer blast analysis showed that the primer was specific to the T. brucei MRPE gene only. The primer was expected to amplify an amplicon containing 1116 nucleotides. However, the sequence BLAST analysis demonstrated that the MRPE gene is 936 nucleotides long, suggesting the actual gene is shorter than the predicted length. The most similar gene determined by NCBI blast was the T. brucei gambiense MRPE gene, DAL972 (XM_011774747.1). Its sequence similarity percentage was as high as $99.79 \%$ (Figure-1). This finding is in agreement with the previous
Table-3: The ligand name prediction and residual binding sites of the $T$. evansi MRPE protein.

\begin{tabular}{lllc}
\hline Rank & C-score Ligand name & $\begin{array}{c}\text { Ligand binding site } \\
\text { residues }\end{array}$ \\
\hline 1 & 0.81 & ANP PMP & $5,12,32,33,34,35$ \\
$36,37,38,66,178$ \\
2 & 0.17 & NA & $37,66,145,146$ \\
3 & 0.15 & ATP & $120,121,122,123,124$ \\
4 & 0.02 & 128 & 125 \\
5 & 0.01 & ALF & $5,10,12,33,34,35$ \\
$36,37,38,41,48$ \\
5
\end{tabular}

C-score is the confidence score of the prediction.

C-score ranges (0-1), where a higher score indicates a more reliable prediction. $T$. evansi $\mathrm{MRPE}=$ Trypanosoma evansi Multidrug Resistance Protein $\mathrm{E}, \mathrm{ALF}=$ Aluminate ion, ATP=Adenosine triphosphate, ANP PMP=Adenylyl imidodiphosphate

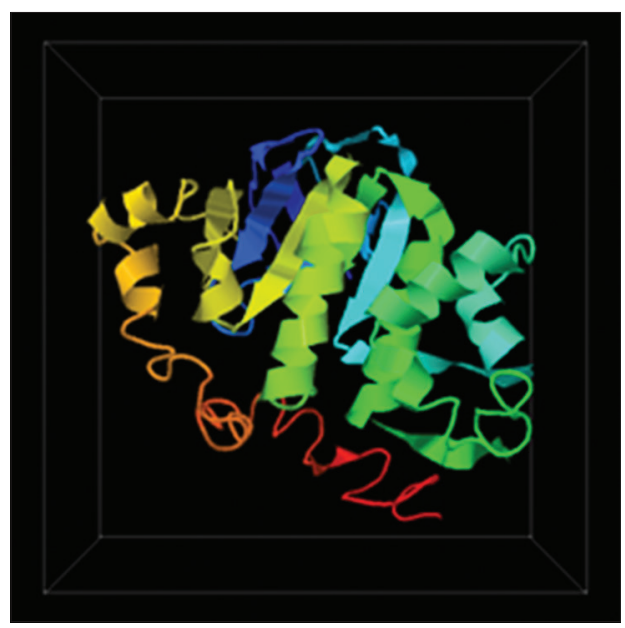

Figure-3: The prediction model of the highest C-score $(-0.66)$ Trypanosoma evansi Multidrug resistance protein E structure

research that reported a relationship between $T$. brucei gambiense and T. evansi based on their MRPE gene sequences [13]. This observation is consistent with the idea that $T$. brucei has evolved, bearing several sub-species such as T. brucei brucei, T. brucei equiperdum, T. brucei gambiense, and Trypanosoma brucei evansi [15]. Furthermore, the evolution of these sub-species was found in the mitochondrial genes of T. brucei spp. $[1,16]$.

Likewise, the protein alignment results of the TevMRPE protein depicted a high similarity percentage (100\%) with the Trypanosoma brucei equiperdum MRPA protein (Table-1). T. evansi belongs to the same clade of $T$. brucei sub-species. Interestingly, T. evansi 
Table-4: The gene ontology of the T. evansi MRPE protein.

\begin{tabular}{lccccc}
\hline Molecular function & GO-score Biological process & GO-score Cellular component & GO-score \\
\hline ATP-binding (GO:0005524) & 0.95 & $\begin{array}{l}\text { Transmembrane } \\
\text { transport } \\
\text { (GO:0055085) }\end{array}$ & 0.48 & $\begin{array}{l}\text { Plasma membrane } \\
\text { (GO:0005886) }\end{array}$ & 0.48 \\
$\begin{array}{l}\text { ATPase-coupled transmembrane } \\
\text { transporter activity (GO:0042626) }\end{array}$ & 0.48 & $\begin{array}{l}\text { Obsolete ATP catabolic } \\
\text { process (GO:0006200) }\end{array}$ & 0.48 & $\begin{array}{l}\text { Integral component } \\
\text { of membrane } \\
\text { (GO:0016021) }\end{array}$ & 0.48 \\
\hline
\end{tabular}

The GO-score is a combined measure for evaluating global and local similarity between query and template protein. Its range is $0-1$ and higher values indicate more confident predictions. $T$. evansi MRPE=Trypanosoma evansi Multidrug Resistance Protein $\mathrm{E}$, ATP=Adenosine triphosphate

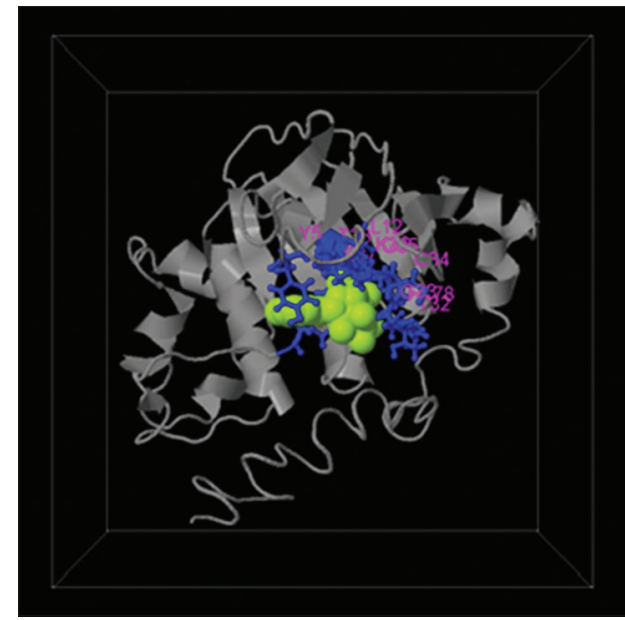

Figure-4: The prediction structure of the highest C-score ligand site (0.8) in Trypanosoma evansi multidrug resistance protein $\mathrm{E}$.

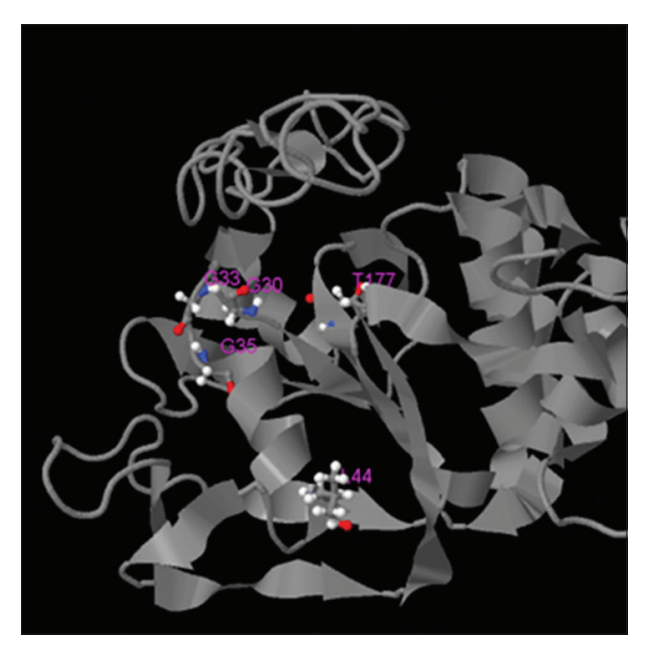

Figure-5: The prediction structure of enzyme commission active site in Trypanosoma evansi multidrug resistance protein $\mathrm{E}$.

and T. brucei genomes are not that similar as the only overlapping sequences between the two are contained to one minicircle of genetic material $[17,18]$. In contrast, the differences between $T$. equiperdum and $T$. evansi are contained in maxicircle kDNA. The maxicircle found in T. equiperdum is bigger compared to $T$. evansi's, suggesting it was reduced by a deletion process [19].

The TevMRPE putative gene had high similarity to the T. equiperdum MRPA gene, suggesting that these genes are well conserved at the sub-species level [20]. Many studies have identified that MRPE is a $\mathrm{C}$ type $\mathrm{ABC}$ transporter characterized by a long N-terminus hydrophilic transmembrane domain, which possesses a protein region of high homology [21-24]. The putative TevMRPE protein sequence in Figure-2 showed that there are five conservative areas among the $\mathrm{ABC}$ transporter family; the $\mathrm{ABC}$ transporter signature motif, the H-Loop/switch region, the Walker B D-Loop, the Walker A/P-loop, and the Q-loop [25,26]. These domains are important for identifying $\mathrm{ABC}$ transporters among other transporter proteins.

The threading protein prediction results (Table-2) showed that the TevMRPE protein had high similarity to three template sequences. The three proteins were the Human MRP 1 NBD1 (2CBZ) protein, the Human ABCC NBD1 in Apo-state (6BZS) protein, and the Cyanidioschyzon merolae $\mathrm{ABC}$ multidrug transporter protein. All of these template proteins are $\mathrm{ABC}$ transporter proteins. This was no surprise as the $\mathrm{ABC}$ transporter protein is the largest protein superfamily that is well conserved across all organism [27]. Of the five protein models compared to the MRPE structure, the first model was (2CBZ) the best representation with an estimated TM-score of $0.63 \pm 0.14$ and estimated RMSD of $7.3 \pm 4.2 \AA$. As no previous MRPE T. evansi protein model published in PDB, the five protein models were the closest model resemble the MRPE of $T$. evansi.

The ligand site prediction showed five ligand sites: ANP, Sodium ion (NA), ATP, 128 Spiro (2,4,6-trinitrobenzene [1,2a]-2o',3o'- methyleneadenine- triphosphate), and Tetrafluoro aluminate ion. The five predicted ligand sites are commonly found in transporters (Table-3 and Figure-4). These findings agree with the previous reporting that MRPs play a crucial role as active transporters with three potential membrane-spanning domains $[28,29]$. Conserved gene organization and protein structure features suggest that MRP and its related proteins share a similar ancestry with the cystic fibrosis conductance regulator [30,31].

The ANP ligand site has an analog function with ATP-binding oxygen atoms with beta- and gamma-phosphate groups. This enables ANP to serve as a potential competitive mitochondrial ATPase inhibitor, the major protein that functions in ATP 
production and regulated by oxidative phosphorylation output [32].

The predicted EC number results showed that the putative MRPE protein is strongly related to other transmembrane transporters involved in trypanocidal resistance. The most similar transmembrane transport protein identified was $1 \mathrm{r} 0 \mathrm{zC}$, which is known as the phosphorylated CFTR containing NBD1. CFTR is an $\mathrm{ABC}$ transporter that functions as a chloride channel $[33,34]$. NBD1, one of two ABC domains in CFTR, also contains sites for cystic fibrosis causing mutations in regulatory phosphorylation sites [35].

Gene ontology prediction showed that MRPE's main function is as a transmembrane transporter and is located in cell plasma membranes (Table-4). This information is consistent with the previous $\mathrm{ABC}$ transporter protein structure reports [36]. These proteins are composed of two transmembrane hydrophobic (TMD) domains involved in substrate translocation. In addition, the NBD is responsible for ATP binding and hydrolysis.

The main function of an $\mathrm{ABC}$ transporter protein is exporting various cellular materials outside of the cell. Baker et al. [7] show that as melarsoprol penetrated Trypanosoma cells, the increase of ABC transporter work increased. Likewise, Delespaux et al. [9] found that isometamidium resistance in $T$. congolens is determined by the insertion of GAA codon in ABC transporter coding gene. These data and our study support the idea that $\mathrm{ABC}$ transport proteins in T. evansi are necessary for the bacteria's resistance to many drugs. Some of the MRP members have five additional transmembrane segments in their N-terminus, but the function of these additional membrane-spanning domains is not clear. Typically, MRP exports glutathione, glucuronate, and sulfate from specific drug stimulation $[31,37]$. Thus, MRP may be a transporter protein that plays an active role in increasing the number of trypanocidal drug resistance cases, especially with cases using thiol conjugates, ivermectin, melarsoprol and benznidazole $[10,11]$.

\section{Conclusion}

This study isolated the gene MRPE, also known as TevMRPE, from T. evansi is homologous to the T. brucei gambiense MRPE gene. This gene is predicted to have an active ligand site for AMP-PMP and active enzyme site similar to that of the CFTR. These ABC transporter superfamily characteristics may be important for the transporting functions responsible for trypanocidal drug resistance in T. evansi.

\section{Authors' Contributions}

RWN planned the entire research work. MMN and DF carried out the laboratory work and sample collection and analyzed the Bioinformatic data. IH administered the research work and analyzed the Bioinformatic data. All authors have read and approved the final manuscript.

\section{Acknowledgments}

The authors acknowledge the financial supports given by Hibah Kompetensi Kemenristekdikti, Republic of Indonesia (Grant Number 1720/UN1/ DITLIT/DIT-LIT/LT/2018) as well as Southeast Asian Regional Center for Graduate Study and Research in Agriculture (SEARCA), headquarter in Los Banos, Philippines, for this research.

\section{Competing Interests}

The authors declare that they have no competing interests.

\section{Publisher's Note}

Veterinary World remains neutral with regard to jurisdictional claims in published institutional affiliation.

\section{References}

1. Desquesnes, M., Holzmuller, P., Lai, D.H., Dargantes, A., Lun, Z.R. and Jittaplapong, S. (2013) Trypanosoma evansi and surra: A review and perspectives on origin, history, distribution, taxonomy, morphology, hosts, and pathogenic effects. Biomed. Res. Int., 2013: 194176.

2. van Vinh Chau, N.V.V., Chau, L.B., Desquesnes, M., Herder, S., Lan, N.P.H., Campbell, J.I., van Cuong, N., Yimming, B., Chalermwong, P., Jittapalapong, S., Franco, J.R., Tue, N.T., Rabaa, M.A., Carrique-Mas, J., Thanh, T.P.T., Vu Thieu, N.T., Berto, A., Hoa, N.T., van Minh Hoang, N., Tu, N.C., Chuyen, N.K., Wills, B., Hien, T.T., Thwaites, G.E., Yacoub, S. and Baker, S. (2016) A clinical and epidemiological investigation of the first reported human infection with the zoonotic parasite Trypanosoma evansi in Southeast Asia. Clin. Infect. Dis., 62(8): 1002-1008.

3. Subekti, D.T. (2014) Perkembangan, struktur, mekanisme kerja dan efikasi trypanosidal untuk surra (Development, structure, mechanism of action and efficacy of trypanocidal for surra). Wartazoa, 24(1): 1-15.

4. Geerts, S., Holmes, P.H., Eisler, M.C. and Diall, O. (2001) African bovine trypanosomiasis: The problem of drug resistance. Trends Parasitol., 17(1): 25-28.

5. Ponnudurai, G., Sivaraman, S., Rani, N. and Veerapandian, C. (2015) An outbreak of trypanosomosis in buffaloes caused by diminazene resistant Trypanosoma evansi. Buffalo Bull., 34(1): 1-4.

6. Subekti, D.T., Yuniarto, I., Sulinawati, S., Susiani, H., Amaliah, F. and Santosa, B. (2015) Trypanocidals effectivity against some isolates of Trypanosoma evansi propagated in mice. J. Ilmu Ternak Vet., 20(4): 275-284.

7. Baker, N., de Koning, H.P., Mäser, P. and Horn, D. (2013) Drug resistance in African trypanosomiasis: The melarsoprol and pentamidine story. Trends Parasitol., 29(3): 110-118.

8. Medina, N.P. and Mingala, C.N. (2016) Transporter protein and drug resistance of Trypanosoma. Ann. Parasitol., 62(1): 11-15.

9. Delespaux, V., Geysen, D., Majiwa, P.A.O. and Geerts, S. (2005) Identification of a genetic marker for isometamidium chloride resistance in Trypanosoma congolense. Int. J. Parasitol., 35(2): 235-243.

10. Ardelli, B.F. (2013) Transport proteins of the ABC systems superfamily and their role in drug action and resistance in nematodes. Parasitol. Int., 62(6): 639-646.

11. Campos, M.C., Phelan, J., Francisco, A.F., Taylor, M.C., Lewis, M.D., Pain, A., Clark, T.G. and Kelly, J.M. (2017) Genome-wide mutagenesis and multidrug resistance in American trypanosomes induced by the front-line drug 
benzimidazole. Sci. Rep., 7(1): 14407.

12. Alibu, V.P., Daunes, S. and D'Silva, C. (2013) N-benzyloxycarbonyl-S-(2, 4-dinitrophenyl) glutathione dibutyl diester is inhibitory to melarsoprol resistant cell lines overexpressing the T. brucei MRPA transporter. Bioorg. Med. Chem. Lett., 23(15): 4351-4353.

13. Nuryady, M.M., Widayanti, R., Nurcahyo, R.W., Fadjrinatha, B. and Fahrurrozi, Z.S.A. (2019) Characterization and phylogenetic analysis of multidrug-resistant protein-encoding genes in Trypanosoma evansi isolated from buffaloes in Ngawi district, Indonesia. Vet. World, 12(10): 1573-1577.

14. Xu, J., Jiao, F. and Yu, L. (2008) Protein structure prediction using threading. Methods Mol. Biol., 413: 91-121.

15. Kamidi, C.M., Saarman, N.P., Dion, K., Mireji, P.O., Ouma, C., Murilla, G., Aksoy, S., Schnaufer, A. and Caccone, A. (2017) Multiple evolutionary origins of Trypanosoma evansi in Kenya. PLoS Negl. Trop. Dis., 11(9): e0005895.

16. Hong, X.K., Zhang, X., Fusco, O.A., Lan, Y.G., Lun, Z.R. and Lai, D.H. (2017) PCR-based identification of Trypanosoma lewisi and Trypanosoma musculi using maxicircle kinetoplast DNA. Acta Trop., 171: 207-212.

17. Molinari, J. and Moreno, S.A. (2018) Trypanosoma brucei Plimmer and Bradford, 1899 is a synonym of T. evansi (Steel, 1885) according to current knowledge and by application of nomenclature rules. Syst. Parasitol., 95(2-3): 249-256.

18. Cooper, S., Wadsworth, E.S., Ochsenreiter, T., Ivens, A., Savill, N.J. and Schnaufer, A. (2019) Assembly and annotation of the mitochondrial minicircle genome of a differentiation-competent strain of Trypanosoma brucei. Nucleic Acids Res., 47(21): 11304-11325.

19. Lun, Z.R., Li, A.X., Chen, X.G., Lu, L.X. and Zhu, X.Q. (2004) Molecular profiles of Trypanosoma brucei, T. evansi and $T$. equiperdum stocks revealed by the random amplified polymorphic DNA method. Parasitol. Res., 92(4): 335-340.

20. Coelho, A.C. and Cotrim, P.C. (2018) The role of ABC transporters in drug-resistant Leishmania. In: Drug Resistance in Leishmania Parasites. Springer International Publishing, Cham. p247-272.

21. Sauvage, V., Aubert, D., Escotte-Binet, S. and Villena, I. (2009) The role of ATP-binding cassette (ABC) proteins in protozoan parasites. Mol. Biochem. Parasitol., 167(2): 81-94.

22. Chen, Z., Shi, T., Zhang, L., Zhu, P., Deng, M., Huang, C., $\mathrm{Hu}$, T., Jiang, L. and Li, J. (2016) Mammalian drug efflux transporters of the ATP binding cassette $(\mathrm{ABC})$ family in multidrug resistance: A review of the past decade. Cancer Lett., 370(1): 153-164.

23. El-Awady, R., Saleh, E., Hashim, A., Soliman, N., Dallah, A., Elrasheed, A. and Elakraa, G. (2016) The role of eukaryotic and prokaryotic $\mathrm{ABC}$ transporter family in failure of chemotherapy. Front. Pharmacol., 7: 535.

24. Fairlamb, A.H. and Horn, D. (2018) Melarsoprol resistance in African trypanosomiasis. Trends Parasitol., 34(6):
481-492.

25. Eckenstaler, R. and Benndorf, R.A. (2020) 3D structure of the transporter ABCG2-what's new? Br. J. Pharmacol., 177(7): 1485-1496.

26. Remali, J., Aizat, W.M., Ng, C.L., Lim, Y.C., MohamedHussein, Z.A. and Fazry, S. (2020) In silico analysis on the functional and structural impact of Rad50 mutations involved in DNA strand break repair. PeerJ., 8: e9197.

27. Zhang, Y. (2008) I-TASSER server for protein 3D structure prediction. BMC Bioinformatics, 9: 40.

28. Costa, K., Salustiano, E.J., Valente, R., Lima, L.F.D., Mendonca-Previato, L. and Previato, J.O. (2020) Thiol Efflux Mediated by an ABCC-Like Transporter Participates for Trypanosoma cruzi Adaptation to Environmental and Chemotherapeutic Stresses, bioRxiv. p1-13.

29. Téllez, J., Romero, I., Romanha, A.J. and Steindel, M. (2019) Drug transporter and oxidative stress gene expression in human macrophages infected with Benznidazolesensitive and naturally Benznidazole-resistant Trypanosoma cruzi parasites treated with Benznidazole, Parasit. Vectors, 12(1): 262.

30. Deeley, R.G. and Cole, S.P.C. (1997) Function, evolution and structure of multidrug resistance protein (MRP). Semin. Cancer Biol., 8(3): 193-204.

31. Leslie, E.M., Deeley, R.G. and Cole, S.P.C. (2005) Multidrug resistance proteins: Role of P-glycoprotein, MRP1, MRP2, and BCRP (ABCG2) in tissue defense. Toxicol. Appl. Pharmacol., 204(3): 216-237.

32. Shafqat, N., Muniz, J.R., Pilka, E.S., Papagrigoriou, E., von Delft, F., Oppermann, U. and Yue, W.W. (2013) Insight into S-adenosylmethionine biosynthesis from the crystal structures of the human methionine adenosyltransferase catalytic and regulatory subunits. Biochem. J., 452(1): 27-36.

33. Liu, F., Zhang, Z., Csanády, L., Gadsby, D.C. and Chen, J. (2017) Molecular structure of the human CFTR ion channel. Cell, 169(1): 85-95.e8.

34. Linsdell, P. (2018) Cystic fibrosis transmembrane conductance regulator (CFTR): Making an ion channel out of an active transporter structure. Channels (Austin), 12(1): 284-290.

35. Lewis, H.A., Buchanan, S.G., Burley, S.K., Conners, K., Dickey, M., Dorwart, M., Fowler, R., Gao, X., Guggino, W.B., Hendrickson, W.A., Hunt, J.F., Kearins, M.C., Lorimer, D., Maloney, P.C., Post, K.W., Rajashankar, K.R., Rutter, M.E., Sauder, J.M., Shriver, S., Thibodeau, P.H., Thomas, P.J., Zhang, M., Zhao, X. and Emtage, S. (2004) Structure of nucleotide-binding domain 1 of the cystic fibrosis transmembrane conductance regulator. EMBO J., 23(2): 282-293

36. Schneider, E. and Hunke, S. (1998) ATP-binding-cassette (ABC) transport systems: Functional and structural aspects of the ATP-hydrolyzing subunits/domains. FEMS Microbiol. Rev., 22(1): 1-20.

37. Johnson, Z.L. and Chen, J. (2017) Structural basis of substrate recognition by the multidrug resistance Protein MRP1. Cell, 168(6): 1075-1085.e9. 